\title{
Poole in the New Keynesian Model*
}

\author{
Fabrice Collard ${ }^{\dagger}$ and Harris Dellas ${ }^{\ddagger}$
}

\begin{abstract}
We study the properties of alternative central bank targeting procedures within the standard New Keynesian model. We find that Poole's famous insights concerning the output stabilization properties of money and interest rate targeting obtain when intertemporal substitution is low. And that output volatility rankings do not induce similar welfare rankings. Unlike the popular presumption, money targeting always fares better for money demand shocks. For fiscal shocks, money targeting does better for low and worse for high degree of intertermporal substitution. The opposite pattern obtains for supply shocks.
\end{abstract}

\section{JEL class: E32 E52}

Keywords: Poole, Money and Interest Rate Targeting, Macroeconomic Volatility, Welfare Rankings

${ }^{*}$ We would like to thank Jordi Galì and two anonymous referees for numerous valuable comments.

${ }^{\dagger}$ CNRS-GREMAQ, Manufacture des Tabacs, bât. F, 21 allée de Brienne, 31000 Toulouse, France. Tel: (33-5) 61-12-85-60, Fax: (33- 5) 61-22-55-63, email: fabrice.collard@gremaq.univ-tlse1.fr, Homepage: http://fabcol.free.fr

${ }^{\ddagger}$ Department of Economics, University of Bern, CEPR, IMOP. Address: VWI, Gesellschaftsstrasse 49, CH 3012 Bern, Switzerland. Tel: (41) 31-6313989, Fax: (41) 31-631-3992, email: harris.dellas@vwi.unibe.ch, Homepage: http://www-vwi.unibe.ch/amakro/dellas.htm 


\section{Introduction}

In the three decades since its publication, the seminal work of Poole [1970] has defined the framework of the theoretical debate in the area of central bank targeting procedures (see Walsh [1998]). It has also exerted a significant influence on actual monetary practices. There has been significant cross country and time series variations in the operating procedures adopted by central banks in the industrial world and the particular choices are often justified by referring to the basic insights of Poole. For instance, as implied by Poole's analysis, the pace of financial innovation and the resulting instability in velocity during the $70 \mathrm{~s}$ and $80 \mathrm{~s}$ created a presumption in favor of interest rate targeting as a means of smoothing fluctuations in aggregate economic activity and inflation. Similarly, the Bundesbank defended its decision to target monetary aggregates by pointing out that velocity in Germany was remarkably stable.

The original analysis of Poole was conducted within the standard textbook IS-LM framework and used output volatility as the sole evaluation criterion. The shortcomings of this model are well known. Canzoneri et al. [1983] redid Poole within the imperfect information, rational expectations model and confirmed that instability in the LM (IS) curve favors interest rate (money supply) targeting. Moreover, within this class of models, the optimal choice of the targeting procedure tends to be ambiguous when supply shocks are the dominant source of macroeconomic instability. The ranking depends on the slope of the IS curve (Blanchard and Fischer [1986]).

A natural question is how Poole's basic insights carry over to the models that are currently used to evaluate monetary policy (computable, dynamic general equilibrium models). And also, whether the rankings of alternative procedures would change if an explicit welfare criterion were adopted. Interestingly, this issue remains relatively unexplored. There have been some works that have asked Poole type of questions, but no existing analysis evaluates the relative performance of interest rate and money targeting for all three types of shocks, namely supply, money and fiscal shocks. Carlstrom and Fuerst [1996] study this issue in a limited participation model with supply and fiscal but no money demand shocks. Galì [2001] and Ireland [2000] address related questions within the context of the New Neoclassical Synthesis (NNS) model. Galì abstracts from money demand shocks while Ireland leaves fiscal shocks out (and he also considers a "soft" interest rate peg, that is one with persistent but variable rates).

The objective of this paper is to examine the properties of alternative targeting procedures in an economy that represents a faithful, general equilibrium rendition of Poole. The model is the standard NNS one, with capital accumulation, staggered prices and three shocks: supply, fiscal and money demand shocks. Four findings stand out. 
First, money targeting generates higher welfare point for money demand shocks independent of the degree of intertemporal substitution (also risk aversion) and the weight attached to real balances in the utility function. This is an interesting result as there is a strong presumption in the literature (that derives from Poole's analysis) that money demand shocks are best dealt with under interest rate pegging. While this is true as far as output stability is concerned we show that it does not extend to welfare comparisons.

Second, the ranking of the two procedures for supply and fiscal shocks depends critically on the value of risk aversion. For supply shocks, interest rate pegging produces better results when risk aversion is high, and worse when risk aversion is low. The opposite pattern obtains for fiscal shocks.

Third, the main insights of Poole concerning output volatility as a function of the targeting procedure and the type of the shock survive intact in the New Keynesian NNS - model only when risk aversion is high. For low risk aversion, money targeting stabilizes output even for fiscal shocks.

There are some differences between our welfare rankings and those found in the existing literature. In section 3, we explain the sources of these differences and also provide a description of the key determinants of the welfare properties of alternative procedures.

The remaining of the paper is organized as follows. Section 1 presents the model. Section 2 describes the choice of parameters and section 3 the main findings concerning the volatility and welfare properties of the two targeting procedures.

\section{The model}

The set up is standard. The economy is populated by a large number of identical infinitely-lived households and consists of two sectors: one producing intermediate goods and the other a final good. The intermediate good is produced with capital and labor and the final good with intermediate goods. The final good is homogeneous and can be used for consumption (private and public) and investment purposes.

\subsection{The Household}

Household preferences are characterized by the lifetime utility function: ${ }^{1}$

$$
E_{t} \sum_{\tau=0}^{\infty} \beta^{\tau} U\left(C_{t+\tau}, \frac{M_{t+\tau}}{P_{t+\tau}}, \ell_{t+\tau} ; \zeta_{t+\tau}\right)
$$

\footnotetext{
${ }^{1} E_{t}($.$) denotes mathematical conditional expectations. Expectations are conditional on information$ available at the beginning of period $t$.
} 
where $0<\beta<1$ is a constant discount factor, $C$ denotes consumption , $M / P$ real balances and $\ell$ leisure. The utility function, $U\left(C, \frac{M}{P}, \ell ;.\right): \mathbb{R}_{+} \times \mathbb{R}_{+} \times[0,1] \longrightarrow \mathbb{R}$ is increasing and concave in its arguments. Finally, $\zeta$ is a stochastic money demand shock that will be defined later.

The household is subject to the following time constraint

$$
\ell_{t}+h_{t}=1
$$

where $h$ denotes hours worked. The total time endowment is normalized to unity.

In each and every period, the representative household faces a budget constraint of the form

$$
B_{t}+M_{t}+P_{t}\left(C_{t}+I_{t}+T_{t}\right) \leq R_{t-1} B_{t-1}+M_{t-1}+N_{t}+\Pi_{t}+P_{t} W_{t} h_{t}+P_{t} z_{t} K_{t}
$$

where $B_{t}$ and $M_{t}$ are nominal bonds and money acquired during period $t, P_{t}$ is the nominal price of the final good, $R_{t}$ is the nominal interest rate, $W_{t}$ and $z_{t}$ are the real wage rate and real rental rate of capital. The household owns $K_{t}$ units of physical capital, makes an additional investment of $I_{t}$, consumes $C_{t}$ and supplies $h_{t}$ units of labor. It pays lump sum taxes $T_{t}$, receives a transfer of money $N_{t}$ from the government and finally claims the profits, $\Pi_{t}$, earned by the firms.

Capital accumulates according to the law of motion

$$
K_{t+1}=I_{t}-\frac{\varphi}{2}\left(\frac{I_{t}}{K_{t}}-\delta\right)^{2} K_{t}+(1-\delta) K_{t}
$$

where $\delta \in[0,1]$ denotes the rate of depreciation. The second term captures the existence of capital adjustment costs.

The household determines her consumption/savings, money holdings and leisure plans by maximizing her utility (1) subject to the time constraint (2), the budget constraint (3) and taking the evolution of physical capital (4) into account.

\subsection{Final sector}

The final good is produced by combining intermediate goods. This process is described by the following CES function

$$
Y_{t}=\left(\int_{0}^{1} X_{t}(i)^{\theta} \mathrm{d} i\right)^{\frac{1}{\theta}}
$$

where $\theta \in(-\infty, 1)$. $\theta$ determines the elasticity of substitution between the various inputs. The producers in this sector are assumed to behave competitively and to determine their demand for each good, $X_{t}(i), i \in(0,1)$ by maximizing the static profit equation

$$
\max _{\left\{X_{t}(i)\right\}_{i \in(0,1)}} P_{t} Y_{t}-\int_{0}^{1} P_{t}(i) X_{t}(i) \mathrm{d} i
$$


subject to (5), where $P_{t}(i)$ denotes the price of intermediate good $i$. This yields demand functions of the form:

$$
X_{t}(i)=\left(\frac{P_{t}(i)}{P_{t}}\right)^{\frac{1}{\theta-1}} Y_{t}
$$

and the following general price index

$$
P_{t}=\left(\int_{0}^{1} P_{t}(i)^{\frac{\theta}{\theta-1}} \mathrm{~d} i\right)^{\frac{\theta-1}{\theta}}
$$

The final good may be used for consumption — private or public — and investment purposes.

\subsection{Intermediate goods producers}

Each firm $i, i \in(0,1)$, produces an intermediate good by means of capital and labor according to a constant returns-to-scale technology, represented by the production function

$$
X_{t}(i)=A_{t} K_{t}(i)^{\alpha} h_{t}(i)^{1-\alpha} \text { with } \alpha \in(0,1)
$$

where $K_{t}(i)$ and $h_{t}(i)$ respectively denote the physical capital and the labor input used by firm $i$ in the production process. $A_{t}$ is an exogenous stationary stochastic technology shock, whose properties will be defined later. Assuming that each firm $i$ operates under perfect competition in the input markets, the firm determines its production plan so as to minimize its total cost

$$
\min _{\left\{K_{t}(i), h_{t}(i)\right\}} P_{t} W_{t} h_{t}(i)+P_{t} z_{t} K_{t}(i)
$$

subject to (9). This leads to the following expression for total costs:

$$
P_{t} S_{t} X_{t}(i)
$$

where the real marginal cost, $S$, is given by $\frac{W_{t}^{1-\alpha} z_{t}^{\alpha}}{\chi A_{t}}$ with $\chi=\alpha^{\alpha}(1-\alpha)^{1-\alpha}$

Intermediate goods producers are monopolistically competitive, and therefore set prices for the good they produce. We follow Calvo [1983] in assuming that firms set their prices for a stochastic number of periods. In each and every period, a firm either gets the chance to adjust its price (an event occurring with probability $\gamma$ ) or it does not. We assume that the price set by the firm incorporates a nominal growth component $\Xi_{t}$, that is the nominal price in period $t$ is $P_{t}(i)=\Xi_{t} p_{t}(i)$ where $p_{t}(i)$ is the deflated fixed price. A firm $i$ sets its price, $\widetilde{p}_{t}(i)$, in period $t$ in order to maximize its discounted profit flow:

$$
\max _{\widetilde{p}_{t}(i)} \widetilde{\Pi}_{t}(i)+E_{t} \sum_{\tau=1}^{\infty} \Phi_{t+\tau}(1-\gamma)^{\tau-1}\left(\gamma \widetilde{\Pi}_{t+\tau}(i)+(1-\gamma) \Pi_{t+\tau}(i)\right)
$$


subject to the total demand it faces

$$
X_{t}(i)=\left(\frac{P_{t}(i)}{P_{t}}\right)^{\frac{1}{\theta-1}} Y_{t}
$$

and where $\widetilde{\Pi}_{t+\tau}(i)=\left(\widetilde{p}_{t+\tau}(i)-P_{t+\tau} S_{t+\tau}\right) X\left(i, s^{t+\tau}\right)$ is the profit attained when the price is reset, while $\Pi_{t+\tau}(i)=\left(\Xi_{t+\tau} \widetilde{p}_{t}(i)-P_{t+\tau} S_{t+\tau}\right) X_{t+\tau}(i)$ is the profit attained when the price is maintained. $\Phi_{t+\tau}$ is an appropriate discount factor related to the way the household values future as opposed to current consumption. This leads to the price setting equation

$$
\widetilde{p}_{t}(i)=\frac{1}{\theta} \frac{E_{t} \sum_{\tau=0}^{\infty}(1-\gamma)^{\tau} \Phi_{t+\tau} \Xi_{t+\tau}^{\frac{1}{\theta-1}} P_{t+\tau}^{\frac{2-\theta}{1-\theta}} S_{t+\tau} Y_{t+\tau}}{E_{t} \sum_{\tau=0}^{\infty}(1-\gamma)^{\tau} \Phi_{t+\tau} \Xi_{t+\tau}^{\frac{\theta}{\theta-1}} P_{t+\tau}^{\frac{1}{\theta-1}} Y_{t+\tau}}
$$

Since the price setting scheme is independent of any firm specific characteristic, all firms that reset their prices will choose the same price.

In each period, a fraction $\gamma$ of contracts ends, so there are $\gamma(1-\gamma)$ contracts surviving from period $t-1$, and therefore $\gamma(1-\gamma)^{j}$ from period $t-j$. Hence, from (8), the aggregate intermediate price index is given by

$$
P_{t}=\left(\sum_{i=0}^{\infty} \gamma(1-\gamma)^{i}\left(\Xi_{t-i} \widetilde{p}_{t-i}\right)^{\frac{\theta}{\theta-1}}\right)^{\frac{\theta-1}{\theta}}
$$

\subsection{The monetary authorities}

We consider two types of policy rules. Under the first rule, the central bank simply targets the growth rate of the money supply

$$
\mu_{t}=\bar{\mu}
$$

The nominal interest rate then adjusts to clear the money market.

Under the second policy, the central bank targets the nominal interest. ${ }^{2}$ In this case, the money supply adjusts in order to clear the money market.

\subsection{The government}

The government finances government expenditure on the domestic final good using lump sum taxes. The stationary component of government expenditures is assumed to follow an exogenous stochastic process, whose properties will be defined later.

\footnotetext{
${ }^{2}$ In order to avoid the well known indeterminacy problems, we have specified this rule as follows$$
\widehat{R}_{t}=\rho \widehat{R}_{t-1}+(1-\rho) k_{\pi} \widehat{\pi}_{t} \text { with } \rho=0.999 \text { and } k_{\pi}=1.001
$$

where $\pi_{t}$ is the rate of inflation and $\widehat{a}$ stands for $\log$-deviations from the deterministic steady state. 


\subsection{The equilibrium}

We now turn to the description of the equilibrium of the economy.

Definition 1 An equilibrium of this economy is a sequence of prices $\left\{\mathcal{P}_{t}\right\}_{t=0}^{\infty}=\left\{W_{t}, z_{t}, P_{t}, R_{t}\right.$, $\left.P_{t}(i), i \in(0,1)\right\}_{t=0}^{\infty}$ and a sequence of quantities $\left\{\mathcal{Q}_{t}\right\}_{t=0}^{\infty}=\left\{\left\{\mathcal{Q}_{t}^{H}\right\}_{t=0}^{\infty},\left\{\mathcal{Q}_{t}^{F}\right\}_{t=0}^{\infty}\right\}$ with

$$
\begin{aligned}
& \left\{\mathcal{Q}_{t}^{H}\right\}_{t=0}^{\infty}=\left\{C_{t}, I_{t}, B_{t}, K_{t+1}, h_{t}, M_{t}\right\} \\
& \left\{\mathcal{Q}_{t}^{H}\right\}_{t=0}^{\infty}=\left\{Y_{t}, X_{t}(i), K_{t}(i), h_{t}(i) ; i \in(0,1)\right\}_{t=0}^{\infty}
\end{aligned}
$$

such that:

(i) given a sequence of prices $\left\{\mathcal{P}_{t}\right\}_{t=0}^{\infty}$ and a sequence of shocks, $\left\{\mathcal{Q}_{t}^{H}\right\}_{t=0}^{\infty}$ is a solution to the representative household's problem;

(ii) given a sequence of prices $\left\{\mathcal{P}_{t}\right\}_{t=0}^{\infty}$ and a sequence of shocks, $\left\{\mathcal{Q}_{t}^{F}\right\}_{t=0}^{\infty}$ is a solution to the representative firms' problem;

(iii) given a sequence of quantities $\left\{\mathcal{Q}_{t}\right\}_{t=0}^{\infty}$ and a sequence of shocks, $\left\{\mathcal{P}_{t}\right\}_{t=0}^{\infty}$ clears the markets

$$
\begin{aligned}
Y_{t} & =C_{t}+I_{t}+G_{t} \\
h_{t} & =\int_{0}^{1} h_{t}(i) d i \\
K_{t} & =\int_{0}^{1} K_{t}(i) d i \\
G_{t} & =T_{t}
\end{aligned}
$$

and the money market.

(iv) Prices satisfy (10) and (11).

\section{Calibration}

The model is parameterized on US quarterly data for the period 1960:1-2000:4. The data are taken from the Federal Reserve Database. ${ }^{3}$ The parameters are reported in table 1 .

The nominal growth of the economy is set equal to the sample average of the rate of growth of M1 over the period, implying $\bar{\mu}=2.6 \%$ per quarter. The quarterly depreciation rate, $\delta$, is 0.025 implying an annual depreciation of about $10 \%$. $\theta$ is set such that markups in the economy are $20 \%$. $\alpha$, the elasticity of the production function to physical capital,

\footnotetext{
${ }^{3}$ URL: http://research.stlouisfed.org/fred/
} 
Table 1: Calibration: Benchmark case

\begin{tabular}{|c|c|c|}
\hline \multicolumn{3}{|l|}{ Technology } \\
\hline Capital elasticity of intermediate output & $\alpha$ & 0.2500 \\
\hline Capital adjustment costs parameter & $\varphi$ & 10.0000 \\
\hline Depreciation rate & $\delta$ & 0.0250 \\
\hline Parameter of markup & $\theta$ & 0.8000 \\
\hline Probability of price resetting & $q$ & 0.2500 \\
\hline \multicolumn{3}{|l|}{ Preferences } \\
\hline Discount factor & $\beta$ & 0.9880 \\
\hline Relative risk aversion & $\sigma$ & 1.5000 \\
\hline Parameter of CES in utility function & $\eta$ & -1.5600 \\
\hline Weight of money in the utility function & $\zeta$ & 0.0649 \\
\hline CES weight in utility function & $\nu$ & 0.3405 \\
\hline \multicolumn{3}{|l|}{ Shocks } \\
\hline Persistence of technology shock & $\rho_{a}$ & 0.9500 \\
\hline Standard deviation of technology shock & $\sigma_{a}$ & 0.0079 \\
\hline Persistence of government spending shock & $\rho_{g}$ & 0.9696 \\
\hline Volatility of government spending shock & $\sigma_{g}$ & 0.0098 \\
\hline Persistence of money demand shock & $\rho_{\zeta}$ & 0.9500 \\
\hline Volatility of money demand shock & $\sigma_{\zeta}$ & 0.0180 \\
\hline
\end{tabular}

is set such that the model reproduces the US labor share - defined as the ratio of labor compensation over GDP - over the sample period (0.575). $a_{t}=\log \left(A_{t} / A\right)$ is assumed to follow a stationary $\mathrm{AR}(1)$ process of the form

$$
a_{t}=\rho_{a} a_{t-1}+\varepsilon_{a, t}
$$

with $\left|\rho_{a}\right|<1$ and $\varepsilon_{a, t} \rightsquigarrow \mathcal{N}\left(0, \sigma_{a}^{2}\right)$. We set $\sigma_{a}=0.0079$ and $\rho_{a}=0.95$.

The standard NNS model has the propensity to generate a negative relationship between supply shocks and output when prices are very sticky, risk aversion is high and capital adjustment costs low. We do not want our model to have this property under any of the parameter configurations used here. We set $\varphi=10$ which means that increasing the investment capital ratio from its steady state value by one percentage point requires that about $1 \%$ of the new investment be used to pay for capital adjustment. This value of $\varphi$ is sufficient to generate a positive relationship between supply shocks and output even under the least favorable configuration employed, namely $\sigma=3.5$ and $\gamma=0.25$. Note that much larger values have been used in the literature. For instance, Ireland [2000] sets $\varphi=40$, following the suggestion by King and Watson [1996] that high adjustment costs are necessary in order to generate sensible response of output to monetary shocks. 
The government spending shock ${ }^{4}$ is assumed to follow an $\operatorname{AR}(1)$ process

$$
\log \left(g_{t}\right)=\rho_{g} \log \left(g_{t-1}\right)+\left(1-\rho_{g}\right) \log (\bar{g})+\varepsilon_{g, t}
$$

with $\left|\rho_{g}\right|<1$ and $\varepsilon_{g, t} \sim \mathcal{N}\left(0, \sigma_{g}^{2}\right)$. Estimating this process over the sample period leads to a persistence parameter, $\rho_{g}$, of 0.9696 and a standard deviation of innovations of $\sigma_{g}=0.0098$. The government spending to output ratio is set to its observed sample average, 0.22 .

The instantaneous utility function takes the form

$$
U\left(C_{t}, \frac{M_{t}}{P_{t}}, \ell_{t}\right)=\frac{1}{1-\sigma}\left[\left(\left(C_{t}^{\eta}+\zeta_{t} \frac{M_{t} \eta}{P_{t}}\right)^{\frac{\nu}{\eta}} \ell_{t}^{1-\nu}\right)^{1-\sigma}-1\right]
$$

where $\zeta$ is the money demand shock. This leads to the following money demand equation

$$
\zeta_{t}\left(\frac{M_{t}}{P_{t} C_{t}}\right)^{\eta-1}=\frac{R_{t}-1}{R_{t}}
$$

$\sigma$, the coefficient ruling risk aversion, is set equal to 1.5 in the benchmark case. But we also carry out the analysis for alternative values (namely 0.5 and 3.5) as a means of assessing its role in the performance of monetary policy rules. It has been pointed out in the literature (for instance, Galì [2001]) that variations in the value of this parameter makes a difference for the properties of alternative rules. $\eta$ is borrowed from Chari et al. [2000], who estimated it on postwar US data. $\nu$ is set such that the model generates a total fraction of time devoted to market activities of $31 \%$. $\beta$, the discount factor is set such that households discount the future at a $4 \%$ annual rate.

The average value of $\zeta$ is set such that the model mimics the average ratio of M1 money to nominal consumption expenditures ${ }^{5}$ in the US data $(M 1 / P C=1.245)$, which gives $\zeta=0.0649$. The money demand shock also follows an $\operatorname{AR}(1)$ process

$$
\log \left(\zeta_{t}\right)=\rho_{\zeta} \log \left(\zeta_{t-1}\right)+\left(1-\rho_{\zeta}\right) \log (\bar{\zeta})+\varepsilon_{\zeta, t}
$$

with $\left|\rho_{\zeta}\right|<1$ and $\varepsilon_{\zeta, t} \sim \mathcal{N}\left(0, \sigma_{\zeta}^{2}\right)$. We use parameter values estimated by Ireland [2001], namely, $\rho_{\zeta}=0.95$ and $\sigma_{\zeta}=0.018$.

$\gamma$, the probability of price resetting is set in the benchmark case at 0.25 , implying that the average length of price contracts is 4 quarters.

\footnotetext{
${ }^{4}$ The logarithm of the government expenditures are first detrended using a linear trend.

${ }^{5}$ This ratio exhibits a strong negative trend after 1980 . The sample average over the latter period is $M 1 / P C=0.75$. Using this lower value does not affect any of our results, and only brings about a very small reduction in welfare. The results reported are also robust to using any $M 1 / P C$ value from the sample period.
} 


\section{The results}

The model is solved using a second order perturbation method as described in Sims [1998] and Schmitt-Grohe and Uribe [2001]. Indeed, the quadratic approximation, by breaking the certainty equivalence property that characterizes the standard log-linear approximation, delivers more accurate welfare results. In both cases, the level of welfare is computed relying on Monte-Carlo experiments. We simulate series for consumption $(c)$, real balances $(M / P)$, leisure $(\ell)$ and the money demand shock $(\zeta)$ and then feed them into the utility function in order to compute welfare. Each series has a length $\mathrm{T}=10000{ }^{6}$ Each experiment is repeated 2500 times and the results are averaged. Table 3 reports the elasticities of the key variables with regard to the individual shocks. Tables $4-5$ describe the properties of the two targeting rules for $\gamma=0.25$, which corresponds to an average duration of the price contracts of 4 quarters, and various values of $\sigma$. Table 4 reports welfare as well as the variability of the three components of utility, namely, consumption, real balances and leisure. Table 5 gives the volatilities for output and inflation.

The main patterns are (i) that rankings based on output stability and welfare do not always coincide, and (ii) that the degree of intertemporal substitution matters for both macroeconomic performance and welfare. Table 2 sums up the welfare results.

Table 2: Monetary policy delivering higher welfare

\begin{tabular}{|c|c|c|}
\hline$\sigma$ & Shock & $\gamma=0.25$ \\
\hline \multirow{3}{*}{0.5} & Supply & MT \\
\hline & Fiscal & $\mathrm{RT}$ \\
\hline & Money demand & MT \\
\hline \multirow{3}{*}{1.5} & Supply & RT \\
\hline & Fiscal & MT \\
\hline & Money demand & MT \\
\hline \multirow{3}{*}{3.5} & Supply & RT \\
\hline & Fiscal & MT \\
\hline & Money demand & MT \\
\hline
\end{tabular}

Note: MT: Money targeting, RT: Nominal interest rate targeting.

In order to understand these results we now describe the sequence of events that follow a particular shock in the benchmark case $(\sigma=1.5$ and $\gamma=0.25)$. Let us first consider a positive supply shock. The first and fourth columns of table 3 report the impact elasticity of output, consumption, the nominal interest rate and money growth under respectively

\footnotetext{
${ }^{6}$ Simulating longer series does not affect our welfare ranking.
} 
$\mathrm{M}$-targeting and $\mathrm{R}$-targeting. Figure 1 reports the dynamics of output, inflation, the nominal interest rate and money growth following a positive supply shock.

Figure 1: IRF to a supply shock
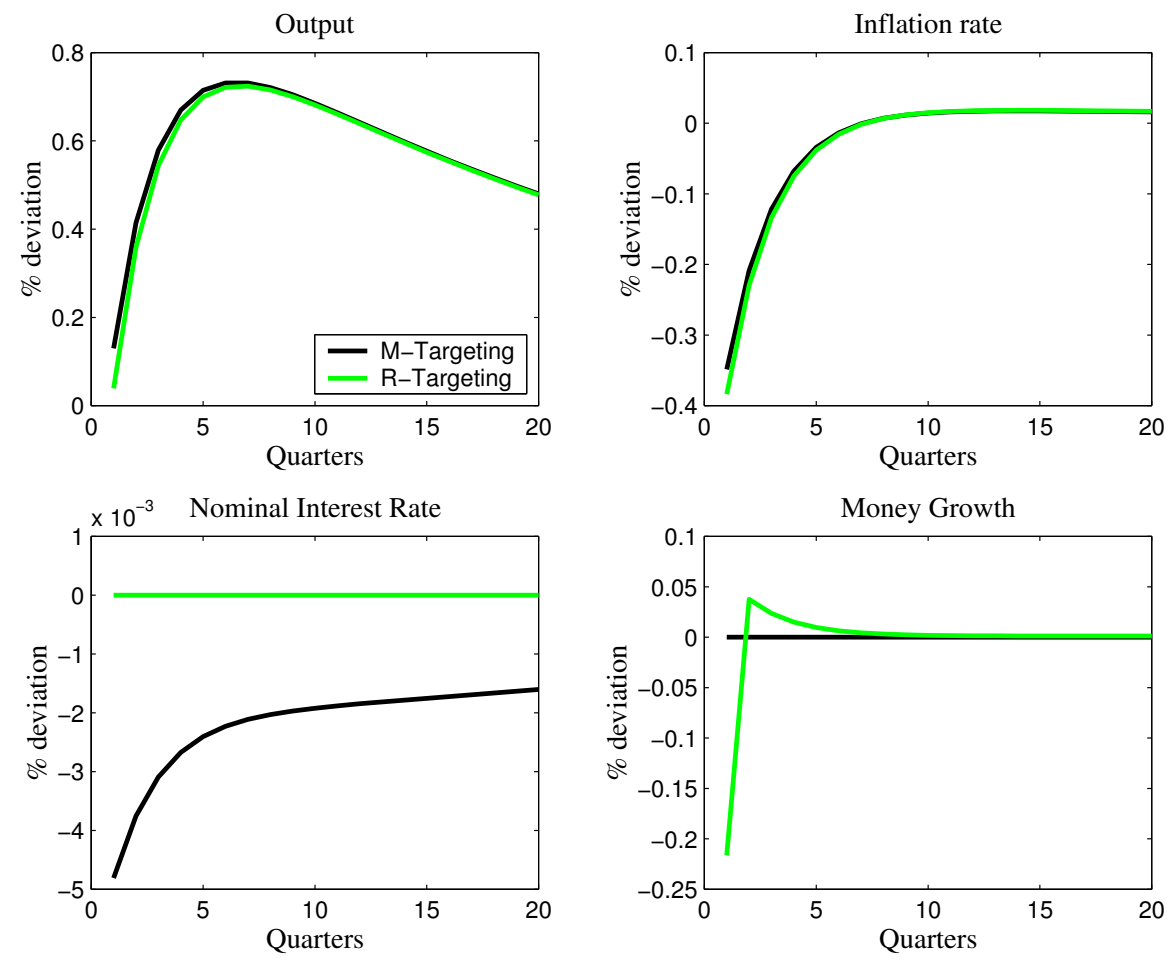

A positive supply shock increases output (first row of each case in table 3) and leads to a persistent, humped shaped increase in consumption. Therefore, the real interest rate increases. At the same time, expected inflation is below its steady state value. If intertemporal substitution is low - as it is the case in our benchmark calibration $(\sigma=1.5)$ — then the latter effect dominates, leading to a lower nominal interest rate ${ }^{7}$.

Under R-targeting, the monetary authority must prevent the decrease in the nominal interest rates by decreasing the growth rate of the supply of money. ${ }^{8}$. Monetary policy is thus conducted countercyclically, which restraints output and consumption variability. As reported in table 5, output variability is 2.55 under $\mathrm{R}$-targeting and 2.59 under $\mathrm{M}$ targeting. The corresponding figures for consumption are 2.86 and 2.91 (see table 4). At the same time, the negative correlation between output and nominal interest rates under M-targeting implies that this procedure also contributes to less stable real balances (3.03

\footnotetext{
${ }^{7}$ If intertemporal substitution is high (say, $\sigma=0.5$ ) the former effect dominates making the nominal interest rate increase.

${ }^{8}$ Note that while a money demand shock has LM-type of effects on output and the nominal interest rate (it moves output and interest rates in opposite directions), a money supply shock does not, at least in the benchmark specification. For instance, a positive money supply shock is always expansionary but does not result in lower nominal interest rates unless risk aversion, adjustment costs and persistence in the money supply growth is low .
} 
Table 3: Elasticities: $q=0.25$

\begin{tabular}{lcccccc}
\hline \hline & \multicolumn{3}{c}{ M-Targeting } & \multicolumn{3}{c}{$\mathrm{R}$-Targeting } \\
\hline & $A$ & $g$ & $\zeta$ & $A$ & $g$ & $\zeta$ \\
\hline \multicolumn{7}{c}{$\sigma=0.50$} \\
\hline$y$ & 0.196 & 0.248 & -0.216 & 0.316 & 0.215 & -0.013 \\
$c$ & 0.395 & -0.061 & -0.178 & 0.491 & -0.088 & -0.017 \\
$R$ & 0.008 & -0.002 & 0.013 & - & - & - \\
$\mu$ & - & - & - & 0.227 & -0.060 & 0.371 \\
\hline \multicolumn{7}{c}{$\sigma=1.50$} \\
\hline$y$ & 0.159 & 0.255 & -0.226 & 0.039 & 0.288 & -0.010 \\
$c$ & 0.262 & -0.030 & -0.199 & 0.159 & -0.001 & -0.014 \\
$R$ & -0.008 & 0.002 & 0.011 & - & - & - \\
$\mu$ & - & - & - & -0.221 & 0.059 & 0.375 \\
\hline \multicolumn{7}{c}{$\sigma=3.50$} \\
\hline$y$ & 0.101 & 0.265 & -0.241 & -0.508 & 0.434 & -0.005 \\
$c$ & 0.060 & 0.017 & -0.230 & -0.515 & 0.177 & -0.008 \\
$R$ & -0.032 & 0.007 & 0.007 & - & - & - \\
$\mu$ & - & - & - & -1.113 & 0.297 & 0.384 \\
\hline \hline
\end{tabular}

vs 2.89 under $\mathrm{R}$-targeting). Indeed, $\mathrm{R}$-targeting shuts down the interest rate effect on the demand for money, which in this case could have simply amplified the positive effect of higher consumption (equation 17). On the other hand, employment is more variable under $\mathrm{R}$-targeting. Nevertheless, the net effect is that $\mathrm{R}$-targeting fares better.

When intertemporal substitution is high (say, $\sigma=0.5$ ), monetary policy is conducted procyclically in order to prevent the nominal interest rate from changing. This amplifies the initial impact effect of a supply shock on both output (2.45 under R- vs 2.40 under $\mathrm{M}$-targeting) and consumption (2.91 versus 2.84) under $\mathrm{R}$-targeting (see table 5 ). At the same time, real balances are also more stable under M-targeting because of the positive correlation between nominal interest rates and consumption. While employment is more stable under R-targeting, the net effect is that M-targeting fares better for supply shocks when risk aversion is low.

We now turn to the effects of a positive fiscal shock. The impact elasticities of output, consumption, the nominal interest rate and money growth for $\mathrm{M}$-targeting and $\mathrm{R}$-targeting respectively are reported in the second and fifth columns of table 3 . Figure 2 reports the dynamics of output, inflation, the nominal interest rate and money growth following a positive fiscal shock.

We continue to focus on the benchmark case $\sigma=1.5$ and $\gamma=0.25$. As in the textbook case, an increase in government expenditures brings about an increase in both output and the nominal interest rate under M-targeting. 
Table 4: Welfare, log-linear approx. $q=0.25$

\begin{tabular}{lccccccccc}
\hline \hline & & \multicolumn{4}{c}{ M-Targeting } & \multicolumn{4}{c}{$\mathrm{R}$-Targeting } \\
\cline { 3 - 10 } Shock & $\sigma$ & $\mathrm{sd}(\mathrm{c})$ & $\mathrm{sd}(\mathrm{M} / \mathrm{P})$ & $\mathrm{sd}(\ell)$ & Welfare & $\mathrm{sd}(\mathrm{c})$ & $\mathrm{sd}(\mathrm{M} / \mathrm{P})$ & $\mathrm{sd}(\ell)$ & Welfare \\
\hline Supply & 0.50 & 2.84 & 2.71 & 0.54 & -41.361544 & 2.91 & 2.93 & 0.47 & -41.361799 \\
Fiscal & & 0.45 & 0.40 & 0.39 & -41.381399 & 0.48 & 0.48 & 0.37 & -41.381362 \\
Money & & 0.48 & 1.17 & 0.32 & -41.380604 & 0.07 & 2.18 & 0.03 & -41.381107 \\
\hline Supply & 1.50 & 2.91 & 3.03 & 0.55 & -55.021443 & 2.86 & 2.89 & 0.61 & -55.020534 \\
Fiscal & & 0.47 & 0.52 & 0.38 & -55.049856 & 0.46 & 0.46 & 0.40 & -55.049895 \\
Money & & 0.52 & 1.16 & 0.33 & -55.048057 & 0.07 & 2.18 & 0.03 & -55.049064 \\
\hline Supply & 3.50 & 3.04 & 3.56 & 0.55 & -105.493740 & 2.89 & 2.94 & 0.87 & -105.481442 \\
Fiscal & & 0.53 & 0.72 & 0.36 & -105.543272 & 0.51 & 0.52 & 0.46 & -105.543397 \\
Money & 0.57 & 1.15 & 0.34 & -105.536088 & 0.06 & 2.19 & 0.02 & -105.539639 \\
\hline \hline
\end{tabular}

Note: sd: standard deviation.

Table 5: Money and interest rate targeting: Volatility $q=0.25$

\begin{tabular}{lccccc}
\hline \hline & & \multicolumn{2}{c}{ M-Targeting } & \multicolumn{2}{c}{ R-Targeting } \\
\hline Shock & $\sigma$ & $s d(y)$ & $s d(\pi)$ & $s d(y)$ & $s d(\pi)$ \\
\hline Supply & 0.50 & 2.40 & 0.31 & 2.45 & 0.27 \\
Fiscal & & 0.69 & 0.05 & 0.66 & 0.04 \\
Money & & 0.53 & 0.17 & 0.05 & 0.01 \\
All & & 2.55 & 0.36 & 2.54 & 0.27 \\
\hline Supply & 1.50 & 2.59 & 0.34 & 2.55 & 0.38 \\
Fiscal & & 0.63 & 0.06 & 0.66 & 0.07 \\
Money & & 0.54 & 0.18 & 0.04 & 0.00 \\
All & & 2.72 & 0.39 & 2.63 & 0.39 \\
\hline Supply & 3.50 & 2.93 & 0.37 & 2.80 & 0.58 \\
Fiscal & & 0.54 & 0.07 & 0.72 & 0.15 \\
Money & & 0.57 & 0.19 & 0.04 & 0.00 \\
All & & 3.04 & 0.42 & 2.89 & 0.60 \\
\hline \hline
\end{tabular}

Note: sd: standard deviation. 
Figure 2: IRF to a fiscal shock
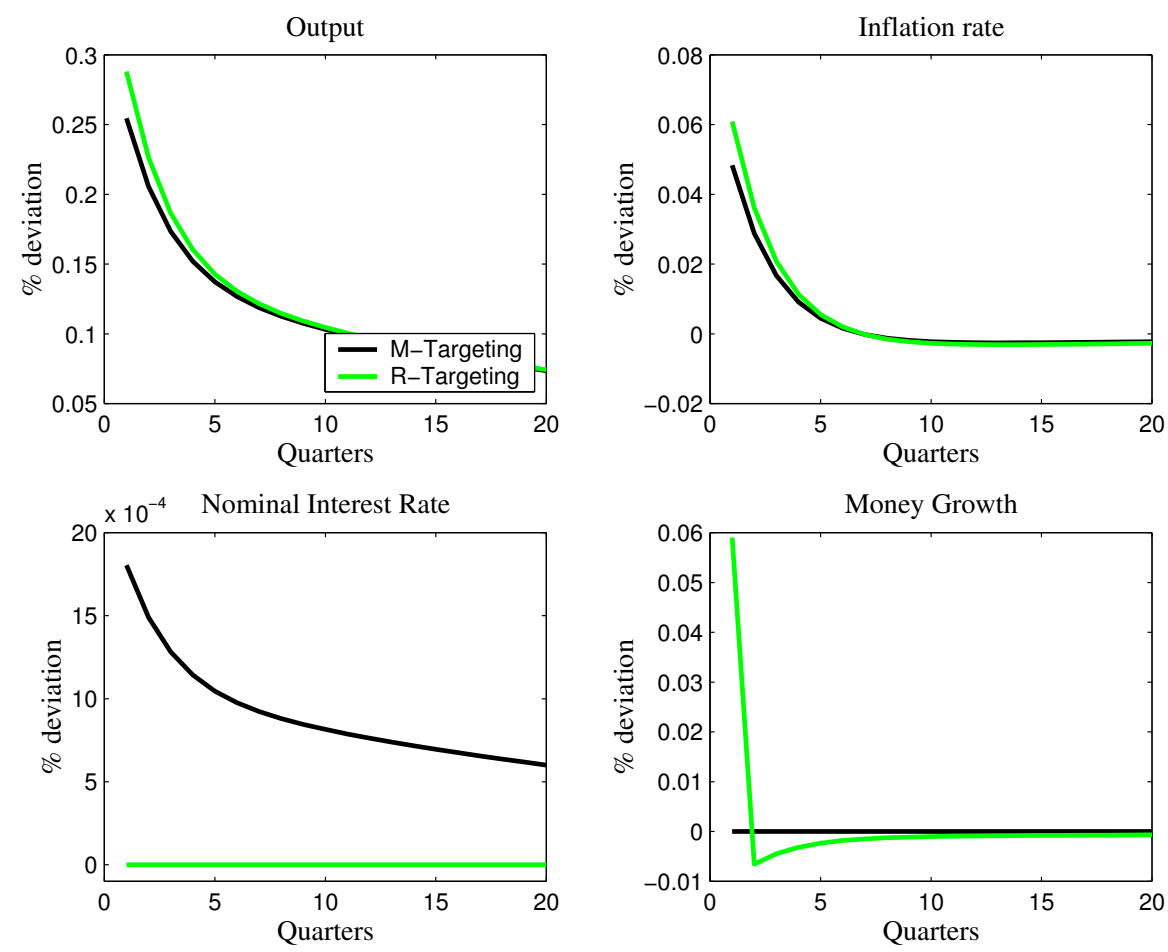

Hence, under R-targeting, the monetary authorities must increase the supply of money in order to prevent the nominal interest rate from rising. This therefore implies procyclical monetary policy, which raises output volatility (0.63 under M- vs 0.66 under $\mathrm{R}$-targeting, see table 5). Notwithstanding its effect on output volatility, $\mathrm{R}$-targeting contributes to more stable consumption and real balances. Indeed, under R-targeting, monetary policy is procyclical with regard to output but countercyclical with regard to consumption. To see this notice that higher government expenditure increases output but crowds out private consumption (table 3). Note also that with lower consumption, expansionary policy not only weakens fluctuations in consumption, but by preventing interest rates from rising, it also stabilizes real balances ${ }^{9}$. On the other hand, $\mathrm{R}$-targeting amplifies fluctuations in leisure. Indeed, as consumption and real balances are less responsive, the negative income effect created by the fiscal shock leads the household to use leisure as a shock absorber to smooth out fluctuations. The latter effect, together with the fact that consumption and leisure move in the same direction under $\mathrm{R}$-targeting, makes this procedure inferior to M-targeting.

It should be noted that the welfare ranking for fiscal and supply shocks derives from differences in the volatility of consumption and leisure across regimes. That is, it would

\footnotetext{
${ }^{9}$ In general, if a supply or fiscal shock under passive money leads to a negative correlation between consumption and nominal interest rates, then $\mathrm{R}$-targeting stabilizes real balances. If it leads to a positive correlation, then $\mathrm{R}$-targeting contributes to real balance instability.
} 
remain valid even when the weight on money in the utility function went to zero (see table 10).

As in the case of a supply shock, high intertemporal substitution alters these results. High intertemporal substitution implies that the nominal interest rate decreases following the positive fiscal shock, which triggers a contraction in the money supply under Rtargeting. Hence, monetary policy becomes is countercyclical and the patterns obtained are the opposite of those described above.

Let us now consider a positive money demand shock. The impact elasticities of output, consumption, the nominal interest rate and money growth are reported in table 3 (third and sixth columns). Figure (3) reports the dynamics of output, inflation, the nominal interest rate and money growth following the shock.

Figure 3: IRF to a money demand shock
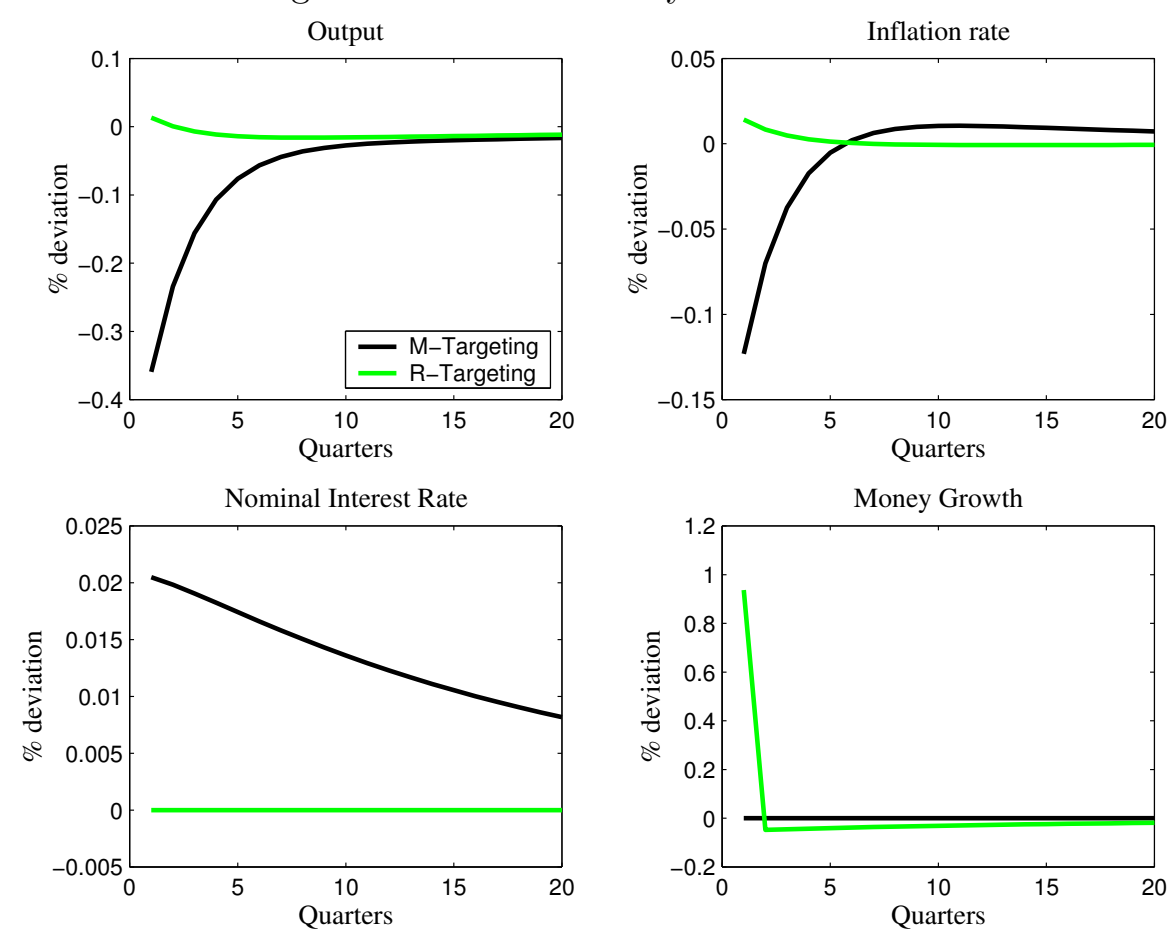

Again, as in the textbook case, under M-targeting such a shock would lower output and consumption and raise nominal interest rates. $\mathrm{R}$-targeting then requires countercyclical monetary policy and hence leads to more stable output and consumption. But the increased consumption stability comes at a cost. By insulating consumption from the effects of the money shock, R-targeting forces real balances to absorb a greater share of the shock than they would have otherwise done (see equation 17). This results in greater real balance volatility. In spite of its greater stability of consumption and 
employment, $\mathrm{R}$-targeting is still dominated by $\mathrm{M}$-targeting. Interestingly, this superiority does not come from the real balance term as it holds even for values of $\zeta$ in the neighborhood of zero (see table 4). It rather comes from the strong negative covariance between consumption and leisure under $\mathrm{M}$-targeting.

The preceding analysis suggests that one particular relationship plays an important role in the comparing of the performance of the two policy rules. Namely, the cyclical behavior of the nominal interest rate with regard to consumption under passive monetary policy. This relationship contains information on whether $\mathrm{R}$-targeting stabilizes consumption and/or real balances. Countercyclical nominal interest rates - under passive monetary policy — create a presumption in favor of $\mathrm{R}$-targeting because such a policy stabilizes both consumption and real balances. It can also be inferred from the tables that the cyclicality of nominal interest rate depends on the type of shock and the degree of risk aversion $(\sigma)$. Only for money demand shocks there is a trade off between consumption and real balance volatility across the two targeting procedures and hence this is the only case in which the value of $\zeta$ might matter. But as shown in the appendix, even in a close neighborhood of the "cash-less" version of the model, M-targeting remains superior for money demand shocks (table 10). That is, even with very small but non-zero values of $\zeta$, M-targeting fares better under money shocks.

The patterns of inflation volatility mirror those of output volatility with the exception of supply shocks. As suggested by the previous analysis, in this case the lower output volatility under $\mathrm{R}$-targeting comes at the cost of higher inflation variability.

The differences in volatility across targeting procedures tend to be modest (except for money demand shocks) when risk aversion is close to unity, but they increase with $\sigma$. As is typically the case in this class of models, these differences translate into even smaller welfare differences. (see tables 13 and 14)

How do our findings compare to those of Poole? The comparison can be made along two dimensions: output volatility and welfare. Concerning the former criterion and for demand shocks (the case considered by Poole), our rankings are identical to his when risk aversion is greater than unity: M-targeting brings about greater output stability for fiscal (IS) shocks while R-targeting fares better for money demand (LM) shocks. In this case, however, our welfare rankings do not perfectly match those based on output stability alone. In particular, while $\mathrm{R}$-targeting brings about greater output stability for money shocks it does not generate higher welfare.

For low risk aversion, the output stability ranking for money demand shocks differ from those of Poole, and the welfare rankings go in the "wrong" direction: R-targeting 
fares better for fiscal and worse for money demand shocks.

In order to check the robustness of our findings against different parameterizations, we report, in appendix B, results with experiments involving an almost "cash-less" version of the model (a very small value for $\zeta$ ) as well as different values for $\eta$ and $\sigma$. As already discussed, the value of $\zeta$ makes almost no differences for welfare, even when $\zeta$ belongs to a close neighborhood of zero. Other than that there is no other difference in the results (see table 11). Moreover, when the utility function approaches the separable case (we set $\sigma=1.001$ and $\eta=-0.1$ ) the differences between the two procedures become negligible for supply and fiscal shocks ${ }^{10}$. They remain important for money demand shocks, and favor R-targeting with a sufficiently high utility weigh for real balances (table 13).

How do our results compare to those reported in similar recent work? In a model similar to ours but without capital and real balances and with separable utility, Galì [2001] finds that M-targeting is welfare superior under both supply and fiscal shocks when $\sigma>1$. And that for the former type of shocks, this superiority increases with the degree of risk aversion. As long as we maintain the assumption that a positive supply shock is expansionary, our model does not deliver superiority for M-targeting under supply shocks no matter what value we use for $\zeta$. As explained above, this result owes to the fact that in our model, nominal interest rates move countercyclically (for $\sigma>1$ ). Naturally, different stochastic processes for technology shocks could generate different combinations of real interest rate and expected inflation movements, and hence different cyclical behavior for nominal interest rates. This is the main source of the difference between our results and those of Galì for supply shocks (Galì assumes an $\operatorname{AR}(1)$ process for productivity growth).

Ireland [1999] compares M-targeting to a Taylor rule with a high degree of interest rate smoothing $(\rho=0.774)$ and a non-negligible reaction coefficient to inflation $\left(\kappa_{\pi}=\right.$ $0.24)$ under supply and money demand shocks. His results on the cyclicality of monetary policy and hence volatility are similar to ours. The main difference from our results is his reporting that $\mathrm{R}$-targeting generates higher welfare for money demand shocks. This seems to reflect the lower weight he attaches to real balances in the utility function $(0.002$ vs 0.05 in our case), the much larger capital adjustment costs he assumes (40 vs 10 in

\footnotetext{
${ }^{10}$ Separability between money and consumption matters for the relationship between money and economic activity. In a model related to ours but without investment, Ireland [2001] argues that money does not enter directly the AS and IS curves if utility is separable. He was not able though to estimate precisely the degree of separability. Note though that money can matter for welfare directly -e.g through the transaction services it provides and so on - even in the absence of an indirect effect. That is, independently of whether utility is separable or not.
} 
our case), and most importantly, the fact that he considers a "soft" peg ( $\rho=0.77$ vs our value of 0.999 ) which transfers a substantial amount of volatility from real balances to the interest rate.

The monetary policies considered in this paper are "ad hoc". The new Keynesian (NK) model has been used extensively as a vehicle for studying optimal monetary policy (Clarida, Galì and Gertler, 1999, Goodfriend and King, 2001, Woodford, 2000). The optimal monetary policy literature has favored a particular version of the NK model, namely, one that abstracts from capital accumulation, where money does not provide any direct services (a "cashless" economy), and where the imperfect competition distortion has been eliminated via a production subsidy. The last assumption makes the flexible price equilibrium first best. As a result, with only the price rigidity distortion remaining, the optimal policy is to perfectly stabilize the price level (or the inflation rate when there exists price indexation of the type employed in our model) because this way the relative price distortion is eliminated and the resulting allocation coincides with that under flexible prices.

The situation, however, is more complex when the economy under consideration is not "cashless" (for instance, when money enters the utility function) and/or no subsidy is used to eliminate the imperfect competition distortion. Abstracting from steady state effects, one can see that in the former case, monetary policy ought to also aim at stabilizing real balances and this requires a deviation from perfect price stabilization (Woodford [2000] Collard and Dellas [2001]). Nevertheless, for a small enough utility weigh on real balances, the deviation from perfectly constant prices is likely to be small (Woodford [2000]).

The properties of optimal monetary policy in the absence of a production subsidy remain an open issue. In a model with one period price contracts and no capital, Adao, Correia and Teles [2000] show that there exist fixed price equilibria which dominate the -inefficient- flexible price equilibrium for reasons related to the zero nominal interest rate bound. However, Khan, King and Wolman [2000] argue that the introduction of overlapping price contracts to the economy studied by Adao, Correia and Teles creates a concern for the relative price distortion caused by price rigidity, and restores the optimality of perfect price stabilization. Moreover, Goodfriend and King [2001] also speculate that this results is not likely to be affected significantly by the presence of capital. However, Collard and Dellas [2002] demonstrate that this is not necessarily the case. That is, that policies tolerating large inflation variability (for instance, monetary targeting) can be welfare superior to a policy of strict inflation targeting in the presence of investment. Nevertheless, these results are only indicative as welfare may not be 
monotone in the variability of inflation (unlike the case considered by Woodford [2000] and others) so it is important to first characterize optimal monetary policy (which has not been accomplished yet) before drawing any firm conclusions about the size of the optimal deviations from perfect price stability.

\section{Conclusions}

The modern literature on monetary policy has been almost exclusively preoccupied with the properties of Taylor type of rules. Nevertheless, given the amount of noise characterizing observations of current inflation and the output gap, we think that useful insights can still be gained by renewing attention to the approach pioneered by Poole. We have used the standard New Neoclassical Synthesis model to revisit Poole's analysis of how the stochastic structure of the economy influences the properties of "pure," passive rules that simply target money or interest rates. The main result is that Poole's insights concerning the relationship between targeting procedures and shocks survive intact when risk aversion exceeds unity. They do not, however, translate into comparable relationships between targeting procedures and welfare. Interest rate targeting fares better for supply shocks while money targeting does better for fiscal and money demand shocks. This latter pattern is exactly the opposite pattern from that one would have inferred on the basis of output stability criteria.

Our analysis has also highlighted the role played for these rankings by the presence of investment decisions, capital adjustment costs, the relative importance of utility services generated by money and the degree of price stickiness. It has, thus, shed light on the sources of differences in welfare rankings across the various works in the existing literature.

In reality, pure procedures such as perfect money or interest rate targeting are rare. Central banks typically use a policy instrument (the monetary base or the interest rate) to respond to observed or perceived shocks. It is then of interest to study what form "optimal" reaction functions for these instruments (as a function of observed state variables) take, what properties they induce into macroeconomic activity and prices and how they are ranked in terms of welfare. We are currently investigating this issue. 


\section{References}

Bernadino Adao, Isabel Correia and Pedro Teles, 2001, Gaps and Triangles, Bank of Portugal, wp. No 2-01.

Blanchard, Olivier and Khan, Charles M., 1980, The Solution of Linear Difference Models under Rational Expectations, Econometrica, 48(5), 1305-1311.

Canzoneri, Matthew, Dale Henderson, and Kenneth Rogoff, 1983, The Information Content of the Interest Rate and the Optimal Monetary Policy, Quarterly Journal of Economics, 98: 545-566.

Carlstrom, Charles and Timothy Fuerst, 1995, Interest Rate Rules vs. Money Growth Rules: A Welfare Comparison in a Cash in Advance Economy, Journal of Monetary Economics, 36 (2): 247-268.

Chari, V., Patrick Kehoe and Ellen McGrattan, 2000, Can Sticky Price Models Generate Volatile and Persistent Real Exchange Rate Changes? NBER working paper, No 7869.

Clarida, Richard, Jordi Galì, and Mark Gertler, 1999, The Science of Monetary Policy: A New Keynesian Perspective, Journal of Economic Literature, 37 (4), 1661-1707.

Collard, Fabrice and Harris Dellas, 2002, Price Rigidity and the Selection of the Exchange Rate Regime, mimeo.

Galì, Jordi, 2001, New Perspectives on Monetary Policy, Inflation, and the Business Cycle, in M. Dewatripont, L. Hansen, and S. Turnovsky eds., Advances in Economic Theory, Cambridge University Press, forthcoming.

Goodfriend, Marvin and Robert G. King, 2001, The Case for Price Stability, NBER wp No. 8423 .

Ireland, Peter, 2000, Interest Rates, Inflation, and Federal Reserve Policy Since 1980, Journal of Money, Credit, and Banking, 32(3), 417-434.

Ireland, Peter, 2001, Money's Role in the Monetary Business Cycle, NBER wp. No 8115.

Khan, Aubhic, Robert G. King and A. Wolman, 2000, Optimal Monetary Policy, mimeo.

King, Robert G. and Mark W. Watson, 1996, Money, Prices, Interest Rates and the Business Cycle, Review of Economics and Statistics 78: 35-53.

Poole, William, 1970, Optimal Choice of Monetary Policy Instruments in a Simple Stochastic Macro Model, Quarterly Journal of Economics 84: 197-216. 
Schmitt-Grohé, S. and M. Uribe, 2001, Solving Dynamic General Equilibrium Models Using a Second-Order Approximation to the Policy Function, mimeo.

Sims, Christopher, 2000, Second Order Accurate Solution of Discrete Time Dynamic Equilibrium Models, mimeo.

Walsh, Carl, 1998, Monetary Theory and Policy, MIT Press.

Woodford, M., 2000, Interest and Prices, manuscript. 


\section{A Alternative parameterizations}

Table 6: Elasticities: $q=0.250, \sigma=1.50, \zeta=10^{-10}$

\begin{tabular}{ccccccc}
\hline & \multicolumn{3}{c}{ M-Targeting } & \multicolumn{3}{c}{ R-Targeting } \\
\hline & $A$ & $g$ & $\zeta$ & $A$ & $g$ & $\zeta$ \\
\hline$y$ & 0.156 & 0.255 & -0.224 & 0.039 & 0.289 & -0.000 \\
$c$ & 0.256 & -0.029 & -0.191 & 0.156 & -0.000 & -0.000 \\
$R$ & -0.008 & 0.002 & 0.012 & - & - & - \\
$\mu$ & - & - & - & -0.223 & 0.060 & 0.391 \\
\hline \hline
\end{tabular}

Table 7: Welfare, $q=0.250, \sigma=1.5, \zeta=10^{-10}$

\begin{tabular}{lcccccccc}
\hline \hline & \multicolumn{4}{c}{ M-Targeting } & \multicolumn{4}{c}{ R-Targeting } \\
\cline { 2 - 9 } Shock & $\mathrm{sd}(\mathrm{c})$ & $\mathrm{sd}(\mathrm{M} / \mathrm{P})$ & $\mathrm{sd}(\ell)$ & Welfare & $\mathrm{sd}(\mathrm{c})$ & $\mathrm{sd}(\mathrm{M} / \mathrm{P})$ & $\mathrm{sd}(\ell)$ & Welfare \\
\hline Supply & 2.90 & 3.02 & 0.55 & -53.321271 & 2.86 & 2.89 & 0.61 & -53.320729 \\
Fiscal & 0.47 & 0.52 & 0.38 & -53.347478 & 0.46 & 0.46 & 0.40 & -53.347521 \\
Money & 0.47 & 1.20 & 0.32 & -53.345499 & 0.00 & 2.25 & 0.00 & -53.346236 \\
\hline \hline
\end{tabular}

Note: sd: standard deviation.

Table 8: Volatility: $q=0.250, \sigma=1.50, \zeta=10^{-10}$

\begin{tabular}{lcccc}
\hline \hline & \multicolumn{2}{c}{ M-Targeting } & \multicolumn{2}{c}{ R-Targeting } \\
\hline shock & $s d(y)$ & $s d(\pi)$ & $s d(y)$ & $s d(\pi)$ \\
\hline Supply & 2.58 & 0.34 & 2.55 & 0.38 \\
Fiscal & 0.63 & 0.06 & 0.66 & 0.07 \\
Money & 0.52 & 0.19 & 0.00 & 0.00 \\
All & 2.71 & 0.39 & 2.63 & 0.39 \\
\hline \hline
\end{tabular}

Note: sd: standard deviation. 
Table 9: Elasticities: $q=0.25, \sigma=1.01, \eta=-0.1$

\begin{tabular}{ccccccc}
\hline \hline & \multicolumn{3}{c}{ M-Targeting } & \multicolumn{3}{c}{ R-Targeting } \\
\hline & $A$ & $g$ & $\zeta$ & $A$ & $g$ & $\zeta$ \\
\hline$y$ & 0.176 & 0.252 & -0.364 & 0.174 & 0.252 & -0.026 \\
$c$ & 0.323 & -0.044 & -0.310 & 0.322 & -0.044 & -0.034 \\
$R$ & -0.000 & 0.000 & 0.020 & -0.000 & 0.000 & -0.000 \\
$\mu$ & 0.000 & 0.000 & 0.000 & 0.003 & 0.000 & 0.870 \\
\hline \hline
\end{tabular}

Table 10: Welfare, log-linear approx. $q=0.250, \sigma=1.01, \eta=-0.1$

\begin{tabular}{lcccccccc}
\hline \hline & \multicolumn{4}{c}{ M-Targeting } & \multicolumn{3}{c}{ R-Targeting } \\
\cline { 2 - 8 } Shock & $\mathrm{sd}(\mathrm{c})$ & $\mathrm{sd}(\mathrm{M} / \mathrm{P})$ & $\mathrm{sd}(\ell)$ & Welfare & $\mathrm{sd}(\mathrm{c})$ & $\mathrm{sd}(\mathrm{M} / \mathrm{P})$ & $\mathrm{sd}(\ell)$ & Welfare \\
\hline Supply & 2.87 & 2.88 & 0.54 & -59.688891 & 2.87 & 2.94 & 0.54 & -59.688787 \\
Fiscal & 0.46 & 0.46 & 0.38 & -59.712876 & 0.46 & 0.47 & 0.38 & -59.712874 \\
Money & 0.82 & 1.90 & 0.53 & -59.725438 & 0.16 & 5.07 & 0.06 & -59.726831 \\
\hline \hline
\end{tabular}

Table 11: Money and interest rate targeting: Volatility $q=0.25, \sigma=1.01, \eta=-0.1$

\begin{tabular}{lcccc}
\hline \hline & \multicolumn{2}{c}{ M-Targeting } & \multicolumn{2}{c}{ R-Targeting } \\
\hline shock & $s d(y)$ & $s d(\pi)$ & $s d(y)$ & $s d(\pi)$ \\
\hline Supply & 2.50 & 0.33 & 2.50 & 0.33 \\
Fiscal & 0.66 & 0.06 & 0.66 & 0.06 \\
Money & 0.88 & 0.29 & 0.10 & 0.01 \\
All & 2.73 & 0.44 & 2.59 & 0.33 \\
\hline \hline
\end{tabular}

Note: sd: standard deviation. 


\section{B Second-order Perturbation Method: A brief summary}

In this section, we provide with a sketchy description of the way we solved the model. Further details can be found in Schmitt-Grohé and Uribe [2001]. Our model takes the form

$$
E_{t} F\left(y_{t+1}, y_{t}, x_{t+1}, x_{t}\right)=0
$$

where $x_{t}$ denotes the $\left(n_{x} \times 1\right)$ state vector $x_{t}$ and $y_{t}$ is a $\left(n_{y} \times 1\right)$ containing all co-state and measurement variables. Therefore, $F: \mathbb{R}^{n_{y}} \times \mathbb{R}^{n_{y}} \times \mathbb{R}^{n_{x}} \times \mathbb{R}^{n_{x}} \longrightarrow \mathbb{R}^{n}$ denotes the model. The total number of variables is given by $n=n_{x}+n_{y}$. We assume that the state vector may be partitioned as $x_{t}=\left[x_{t}^{1} ; x_{t}^{2}\right]$, where $x^{1}$ consists of endogenous state variables, whereas $x^{2}$ consists of exogenous state variables. In order to simplify, let us assume that $x^{2}$ follows the process

$$
x_{t+1}^{2}=M x_{t}^{2}+\eta \Sigma \varepsilon_{t+1}
$$

where $\varepsilon_{t+1}$ is $\left(n_{\varepsilon} \times 1\right)$ and is distributed as a $\mathcal{N}(0, I)$. All eigenvalues of $\mathrm{M}$ are assumed to have modulus less than one.

The solution to this model is of the form:

$$
\begin{aligned}
y_{t} & =g\left(x_{t}, \eta\right) \\
x_{t+1} & =h\left(x_{t}, \eta\right)+\eta \Omega \varepsilon_{t+1} \text { with } \Omega=\left(\begin{array}{c}
0 \\
\Sigma
\end{array}\right)
\end{aligned}
$$

where $g$ maps $\mathbb{R}^{n_{x}} \times \mathbb{R}_{+}$into $\mathbb{R}^{n_{y}}$ and $h$ maps $\mathbb{R}^{n_{x}} \times \mathbb{R}_{+}$into $\mathbb{R}^{n_{x}}$. Making use of the solution, the model can be rewritten as (a prime denotes $t+1$ )

$$
E_{t} \mathcal{F}(x, \eta)=0
$$

where

$$
\mathcal{F}(x, \eta) \equiv F\left(g\left(h(x, \eta)+\eta \Omega \varepsilon^{\prime}, \eta\right), g(x, \eta), h(x, \eta)+\eta \Omega \varepsilon^{\prime}, x\right)
$$

Since neither $g($.$) nor h($.$) can be computed analytically, we take advantage of their$ properties to infer the properties of their slopes and curvatures. The second-order approximation is given by

$$
\begin{aligned}
E_{t} \mathcal{F}^{i}(x, \eta) \simeq E_{t}\left(\mathcal{F}^{i}\left(x^{\star}, 0\right)+\nabla_{x} \mathcal{F}^{i}\left(x^{\star}, 0\right)\left(x-x^{\star}\right)+\nabla_{\eta} \mathcal{F}^{i}\left(x^{\star}, 0\right) \eta\right. \\
\left.+\frac{1}{2}\left(x-x^{\star}, \eta\right) \mathcal{H}_{\mathcal{F}}^{i}\left(\begin{array}{c}
x-x^{\star} \\
\eta
\end{array}\right)\right)=0
\end{aligned}
$$

for all $i=1 \ldots, n$.

The constant terms, $g\left(x^{\star}, 0\right)$ and $h\left(x^{\star}, 0\right)$, correspond to the deterministic steady state of the model. The first order terms $\left(g_{x}\left(x^{\star}, 0\right)\right.$ and $\left.h_{x}\left(x^{\star}, 0\right)\right)$ can be obtained by solving 
a matrix polynomial equation and imposing the requirement that the system returns asymptotically to equilibrium in the absence of other future shocks. This essentially amounts to solving a linear RE model, so any method of the Blanchard and Kahn [1980] type can be used. Furthermore, Schmitt-Grohé and Uribe [2001] showed that both $g_{\eta}\left(x^{\star}, 0\right)$ and $h_{\eta}\left(x^{\star}, 0\right)$ are nil. The second order terms, $g_{x x}\left(x^{\star}, 0\right)$ and $h_{x x}\left(x^{\star}, 0\right)$, can be obtained by solving a linear system and the same procedure applies to $g_{\eta \eta}\left(x^{\star}, 0\right)$ and $h_{\eta \eta}\left(x^{\star}, 0\right)$. As both $g_{x \eta}\left(x^{\star}, 0\right)$ and $h_{x \eta}\left(x^{\star}, 0\right)$ are nil (see Schmitt-Grohé and Uribe [2001]) the approximated decision rule, used to simulate the model, take the form

$$
\begin{aligned}
& g\left(x^{\star}, 0\right)+g_{x}\left(x^{\star}, 0\right)\left(x_{t}-x^{\star}\right)+\frac{1}{2}\left(x_{t}-x^{\star}\right)^{\prime} g_{x x}\left(x^{\star}, 0\right)\left(x_{t}-x^{\star}\right)+\frac{1}{2} g_{\eta \eta}\left(x^{\star}, 0\right) \eta^{2} \\
& h\left(x^{\star}, 0\right)+h_{x}\left(x^{\star}, 0\right)\left(x_{t}-x^{\star}\right)+\frac{1}{2}\left(x_{t}-x^{\star}\right)^{\prime} h_{x x}\left(x^{\star}, 0\right)\left(x_{t}-x^{\star}\right)+\frac{1}{2} h_{\eta \eta}\left(x^{\star}, 0\right) \eta^{2}
\end{aligned}
$$

